\title{
RESILIÊNCIA SOCIOAMBIENTAL DOS AGRICULTORES FAMILIARES NA HINTERLÂNDIA AMAZÔNICA
}

\author{
Maria Isabel de Araújo; ; Silas Garcia Aquino de Sousa² \\ ${ }^{1}$ Mestra em Sociedade e Cultura na Amazônia, UNIFAVENI, Manaus, Amazonas, ${ }^{2}$ Doutor em \\ Engenharia Florestal/Conservação da Natureza, Embrapa, Manaus, Amazonas.
}

DOI: $10.47094 /$ ICONNECA.2021/17

\begin{abstract}
RESUMO
As agroflorestas da hinterlândia amazônica são considerados sistemas de conservação da agrobiodiversidade, resguardados pelo conhecimento tradicional dos agricultores familiares no longo processo de (co)evolução do homem com a natureza. Objetiva o presente elencar uma descrição das práticas do sistema de corte e queima da capoeira (SACQ) versus a inovação tecnológica de sistema de agricultura sem queima (SASQ), em dois sistemas agroflorestais, classificados como "quintal agroflorestal". Embasa a pesquisa no método da pesquisa-ação etnográfica. Os indicadores avaliados evidenciou uma estratégia de resiliência socioambiental com atributo nos princípios de sustentabilidade, frente à necessidade de produzir com menor impacto negativo ao ambiente e maior otimização da produção em beneficio ao bem estar social e econômico dos agricultores familiares. Conclui-se que as práticas de SASQ evidenciam a oferta de serviços ambientais, garantia da dieta alimentar e geração de renda aos agricultores familiares.
\end{abstract}

PALAVRAS-CHAVE: Agricultura familiar; Agrofloresta; Amazônia.

ÁREA TEMÁTICA: Gestão ambiental.

\section{INTRODUÇÃO}

Dentre os tradicionais sistemas de uso da terra, as agroflorestas da hinterlândia amazônica são considerados sistemas de conservação da agrobiodiversidade, resguardados pelo conhecimento tradicional dos agricultores familiares no longo processo de (co)evolução do homem com a natureza, carregados em si de ancestralidade, reflete histórias multiculturais dos povos e comunidades tradicionais.

O manejo equilibrado desse agroecossistema reproduz um conjunto diversificado de condições sociais e ambientais que se entrelaçam de forma indissociável, nas dimensões da sustentabilidade, garantindo a dieta alimentar e geração de renda familiar. 
O sistema de coivara consiste no corte e queima da capoeira (SACQ), prática ancestral dos povos tradicionais, configura-se como método empírico de manejo com o corte e queima da vegetação arbustivo-arbórea nas áreas de pousio ou dos cultivos agrícolas perene e semiperenes abandonadas, para cultivos por curtos períodos, cujo complexo vegetação-cinza-solo constitui-se fonte de nutriente as roças.

Neste contexto, sob a perspectiva dos princípios da sustentabilidade, diferentes propostas que vêm sendo elaboradas na promoção da sustentabilidade ambiental, social e econômica, por meio de tecnologias de baixo impacto em substituição ao tradicional sistema de corte sem queima da capoeira (SASQ), com alternativas econômicas para os agricultores familiares tradicionais.

Dessa forma, objetiva o presente estudo a analise da capacidade de resiliência socioambiental resultante do manejo de dois agroecossistemas, dos agricultores familiares na hinterlândia amazônica, com enfoque na prática do sistema de corte e queima da capoeira (SACQ) versus a inovação tecnológica de sistema de agricultura sem queima (SASQ).

\section{METODOLOGIA}

Utilizou-se nesta pesquisa duas abordagem metodológica que envolveu instrumentos da pesquisa bibliográfica, métodos da pesquisa-ação etnográfica, a partir de um estudo de caso, com aplicação de um sistema de indicadores de sustentabilidade de dimensão ecológica, adaptado do marco conceitual Ambitec-Agro, desenvolvido pela EMBRAPA. A partir das características da pesquisa-ação apontada por THIOLENT (2004, p. 13), que a considera uma pesquisa social, com base empírica, concebida e realizada em estreita associação com uma ação/resolução de um problema coletivo, no qual pesquisadores e participantes estão envolvidos de modo cooperativo e participativo. De forma a inteirar a pesquisa, utilizou-se o método etnográfico proposto por MALINOWSKI (1978) qual considera que os elementos singulares são as partes constitutivas da cultura como um todo integrado, que evolui dinamicamente com a realidade em correspondência com a condição humana [...] sua relação com a vida, bem como a sua visão do mundo" [...] para a apreensão da realidade, o trabalho de campo é condição sine qua non, o que fez dele o mestre do método antropológico da observação participante. (MALINOWSKI,1978, p. 25).

Realizou-se a pesquisa em dois momentos distintos (fevereiro de 2017 e março de 2021, para tanto, considerando as relações de interdependência que se estabelece a resiliência socioambiental e socioeconômica, com visita in loco, em dois sistemas agroflorestais, classificados como "quintal agroflorestal", oriundos de dois estabelecimentos de agricultores familiares (E1 SACQ) e (E2 SASQ), localizados a margem esquerda da BR 174 (Manaus - Boa Vista), km 67, Vicinal ZF4, km 6 e 8, na gleba do Distrito Agropecuário da Suframa, nas coordenadas geográficas $02^{\circ} 25^{\prime 2} 29,15^{\prime \prime S}$ $60^{\circ} 04^{\prime} 10^{\prime \prime} \mathrm{W}$ e $02^{\circ} 24^{\prime} 49.8^{\prime}$ 'S $60^{\circ} 05^{\prime} 02.95$ 'W com área média de 25 ha, zona rural de Manaus/AM. 


\section{RESULTADOS}

Apontam os resultados, que no SASQ todo material vegetal depositado e distribuído sobre o solo gerou melhor condições físicas e biológicas para as plantas cultivadas, retardando a germinação do banco de sementes do solo e regeneração das plantas espontâneas, contribuindo para diminuir as capinas periódica no sistema e favorecendo o estabelecimento das plantas cultivadas, por sementes e mudas, principalmente as culturas temporárias (feijão mandioca). Porém, no decorrer do segundo ano, a resiliência ambiental referente a regeneração e diversificação de plantas espontânea é maior, quando comparado com SACQ. Com essa estratégia, a família pode ser contemplada com a produção da cultura temporária e o melhor desenvolvimento das mudas das espécies perenes. No SACQ o plantio por sementes e mudas dependem de irrigação das chuvas ou artificial, o solo sem cobertura recebe maior insolação e fica exposto a erosão e perda de solo. Dependendo da quantidade de fitomassa queimada (Figura 1), o status de fertilidade do solo é quase insignificante e as plantas cultivadas dependem de maior quantidade de água.

Figura 1: E1 SACQ

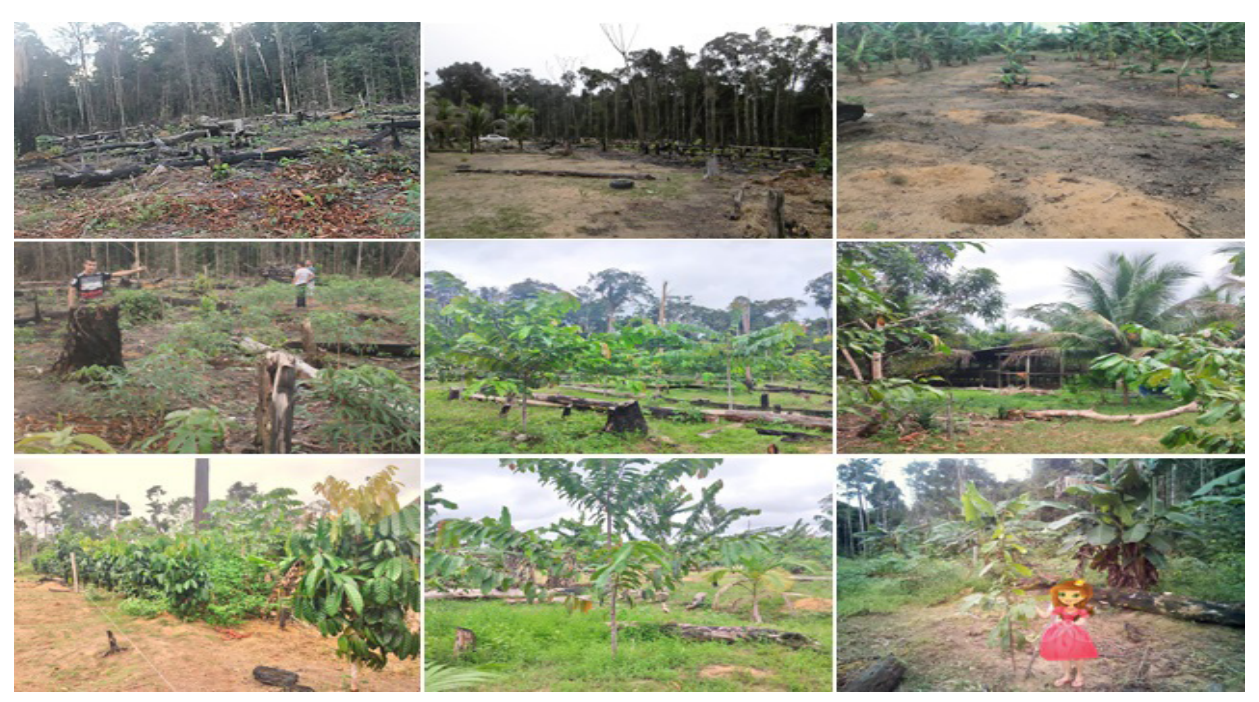

Fonte: ARAÚJO, Maria Isabel. (2017-2021)

A vantagem do SACQ é a deposição de nutrientes para fertilização do solo, decorrente da queima da vegetação secundaria (capoeira), que deveria favorecer o desenvolvimento das plantas, porém, a queima provocou menor umidade no solo e maior incidência de calor e insolação durante o estabelecimento das plantas cultivadas, prejudicando o desenvolvimento vegetal. Capinas periódicas são necessárias pelo menos duas vezes por ano e nem sempre a produtividade das culturas temporárias é melhor do que no SASQ (Figura 2), principalmente se a irrigação for insuficiente. 
Figura 2: E2 SASQ

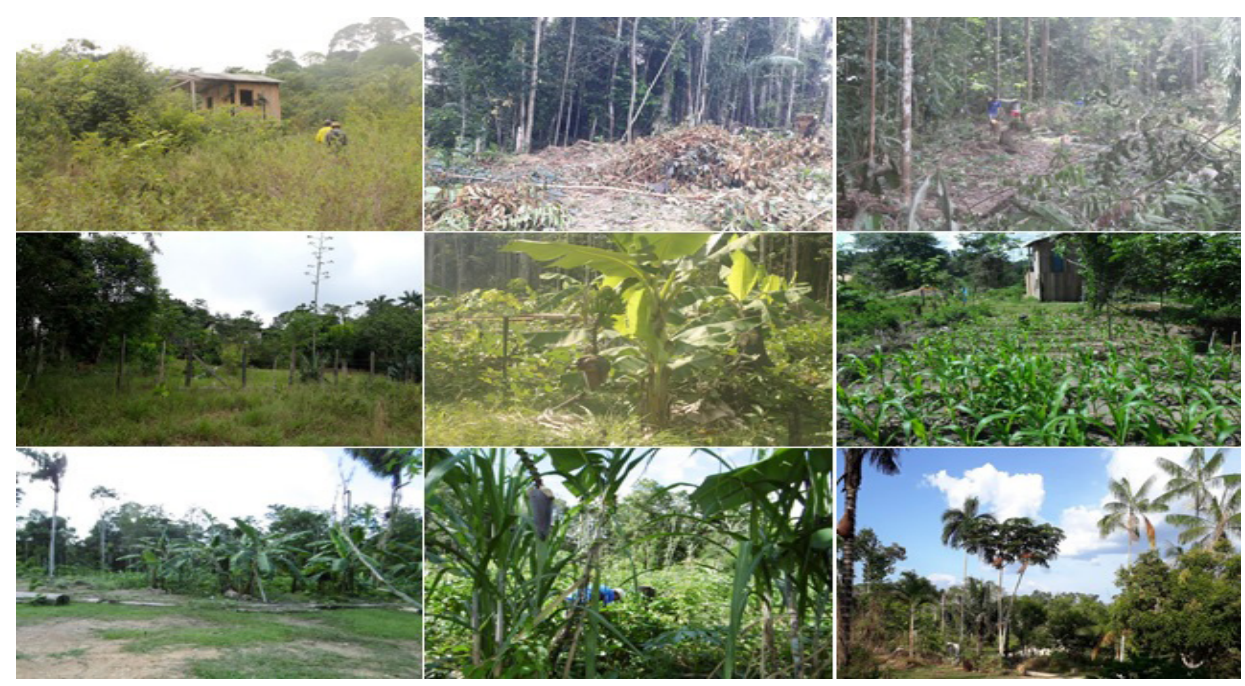

Fonte: ARAÚJO, Maria Isabel. (2017-2021)

A resiliência da regeneração natural proporcionou maior ocorrência de plantas espontâneas de folha estreita (gramíneas) e baixa ocorrência de folhas largas. Com referência a resiliência social e econômica, o agricultor familiar busca nas novas inovações tecnológicas, no caso SASQ, a oportunidade de superar as condições adversas de viver e produzir alimentos procura forças, motivações e capacidade de lutar pela melhoria das condições de vida da família apostando na valorização pelo mercado a produção de alimentos saudáveis de base orgânica aliada as boas práticas agroecológicas.

\section{CONSIDERAÇÕES FINAIS}

O sistema agroflorestal implantado pelo SASQ, evidenciou uma estratégia de resiliência socioambiental com tributo dos princípios de sustentabilidade, frente a necessidade de produzir com menor impacto negativo ao ambiente e maior otimização da produção em beneficio ao bem estar social e econômico dos agricultores familiares. A mudança de paradigma da prática do SACQ para o SASQ reflete a conjectura elisiana na evolução do processo civilizador, com ênfase na relação das teias de interdependência, que o agricultor passa a exercitar como ser social ativo, capaz de construir um ambiente saudável e seguro para o futuro de sua família. Em nossa análise, não foi possível quantificar a resiliência ambiental, considerando o conjunto de variáveis de sistemas complexos, das agroflorestas. Não obstante, a forma como o sistema agroflorestal modificou a paisagem da unidade produtiva chamou atenção, as mudanças que afetaram os agricultores familiares, contribuindo para identificar ameaças e oportunidades futuras e, portanto, a resiliência geral dos sistemas socioambiental e socioeconômico resultado das relações das teias interdependência, no percurso do processo civilizador. 
MALINOWSKI, Bronislaw. A vida sexual dos selvagens. São Paulo: Abril, 1978 (Coleção os Pensadores).

RODRIGUES, G. S. et al. Avaliação de Impacto Ambiental da Inovação Tecnológica Agropecuária: AMBITEC-AGRO. Jaguariúna: Embrapa Meio Ambiente - Documento, 34. 2003.

THIOLLENT, M. J. M. Metodologia da pesquisa-ação. 13. ed. São Paulo: Cortez, 2014. 107p 